
\title{
25 Research Square \\ Effect of carbon nanotubes on the microstructure and properties of CPED ceramic coating
}

Ping Wang ( $\nabla$ wping0922@163.com )

Xi'an Technological University

\section{Xiaomin Chen}

Xi'an Electronic Engineering Research Institute

\section{Chunqing Zhang}

Chengde Petroleum College

Di Jiao

Xi'an Technological University

Shangyi Jiao

Xi'an Technological Universiity

Min Yao

Xi'an Technological University

\section{Research Article}

Keywords: Cathode plasma electrolytic deposition (CPED), Heat insulation performance, Fracture toughness, Toughening of carbon nanotubes

Posted Date: May 15th, 2020

DOI: https://doi.org/10.21203/rs.3.rs-28189/v1

License: (c) (1) This work is licensed under a Creative Commons Attribution 4.0 International License.

Read Full License 


\section{Abstract}

Cathode plasma electrolytic deposition ceramic coating modified by carbon nanotubes was prepared on Al-Si alloy. The microstructure and the heat insulation performance, fracture toughness and bending strength of the coating were investigated by SEM, XRD, the heat insulation test device and tensile testing machine. Carbon nanotubes(CNTs) are staggered in the ceramic layer and partially filled with plasma discharge micropores. To some extent, CNTs can promote the cathode plasma discharge and improve the film formation rate. The content of a-Al2O3 and t-ZrO2 phases increased with the increase of CNTs concentration. A certain amount of carbon nanotubes can effectively improve the insulation temperature of ceramic layer. With the increase of the content of carbon nanotubes, the fracture toughness and bending strength gradually increase.

\section{Introduction}

Cathode plasma electrolytic deposition (CPED) is a hybrid of traditional electrolysis and the atmospheric plasma process, which uses directly the energy of plasma to transform the electrolyte into a complex oxide in one step [1-3]. Therefore, CPED has a simple operation and short process cycle. In addition, the composition of ceramic layer can be adjusted according to the requirement. It is not limited by the substrate shape and has good adhesion [4,5]. However, the current research mainly focuses on the preparation of CPED ceramic layer, corrosion, wear and other properties [6-9]. Generally, the inherent brittleness of ceramic layer makes the mechanical properties of ceramic layer inadequate. However, there are fewer reports on the mechanical properties of CPED ceramic layers [10-13].

The mechanical properties of the ceramic layer can be improved by phase transformation and toughening of particles, whiskers or fibers [14-19]. In particular, ductile particles such as gold, silver and platinum are very helpful to the toughening of ceramic layers. Ma et al. [20] prepared Au nano-particles doped $\mathrm{a}-\mathrm{Al}_{2} \mathrm{O}_{3}$ composite coating on TiAl-based alloy. It indicates that cracks were shielded by means of crack bridging and the fracture resistance can be improved by toughening effects of the composite structure. Wang et al. [21] prepared the porous $\mathrm{a}-\mathrm{Al}_{2} \mathrm{O}_{3}$ thermal barrier coatings (TBCs) containing dispersed Pt particles by cathode plasma electrolytic deposition (CPED). It indicates the coating provides good thermal insulation and exhibit excellent mechanical properties because of the toughening effect of the Pt particles and because of stress relaxation induced by deformation of the porous structure.

Carbon nanotubes(CNTs) have good mechanical properties such as superplasticity and ductility [22, 23]. The research shows that CNTs can self repair and repair defects by kinking and stretching under the action of external forces [24-28]. Therefore, CNTs should be of great help to the toughening of ceramic coating. However, there is no report on the study of CPED ceramic layer toughened by carbon nanotubes.

Al-Si alloys as hot end components, such as pistons, withstand high temperatures and pressures. Therefore, the ceramic layer needs to have good heat resistance and mechanical properties. However, there are few studies on the thermal protection and mechanical properties of CPED coating on Al-Si alloy. 
In the present study, carbon nanotubes was chosen as an additive, and the effect of CNTs on the microstructure and heat-insulating and mechanical properties of CPED coating on a cast Al-12Si alloy were investigated in detail.

\section{Experimental}

Al-12Si-3Cu-2Ni-1 Mg (wt.\%) alloy was used in the experiment. CPED ceramic layer was prepared by plasma electrolytic deposition equipment. In order to induce cathode plasma discharge, PEO method was used to prepare insulating barrier layer. Barrier layer with a thickness of 3 um was prepared for 3 min in silicate solution. The current density was $6 \mathrm{~A} / \mathrm{dm}^{2}$ and frequency was $500 \mathrm{~Hz}$. During the CPED process, the specimen was used as cathode. After deposition for 30 minutes, the current density was $9 \mathrm{~A} / \mathrm{dm}^{2}$ and duty cycle was $20 \%$ in the CPED process. The experimental solution was $\operatorname{Zr}\left(\mathrm{NO}_{3}\right)_{4}(12 \mathrm{~g} / \mathrm{l}), \mathrm{Y}\left(\mathrm{NO}_{3}\right)_{3}$ $(1 \mathrm{~g} / \mathrm{l})$ and CNTs with concentrations between $0.1 \mathrm{~g} / \mathrm{L}$ and $0.9 \mathrm{~g} / \mathrm{L}$.

The microstructure and phase composition of the coatings were tested by SEM and XRD. The heat insulation performance was tested through heat insulation test device. The fracture toughness and bending strength were tested by tensile testing machine.

\section{Results And Discussion}

\subsection{The morphology of CNTs and its influence on arc discharge voltage}

TEM micrograph of CNTs was shown in Fig. 1. As seen in Fig. 1, the length of CNTs was about 0.5 to $2 \mu \mathrm{m}$, the diameter was about 30 to $50 \mathrm{~nm}$, and the ratio of length- diameter was 16:1 to 40:1.

The change of arc discharge voltage of the sample with the content of CNTs in the electrolyte during cathodic plasma electrodeposition was shown in Fig. 2. It can be seen that with the increase of the content of CNTs, the arc discharge voltage first decreased and then increased. When the content of CNTs in the electrolyte is $0.5 \mathrm{~g} / \mathrm{l}$, the arc discharge voltage was the lowest. Due to the good conductivity of CNTs, it can promote the cathode plasma discharge. However, when the content of CNTs reached a certain level, the promoting effect of CNTs on plasma discharge decreased.

\subsection{Effect of CNTs on the microstructure of CPED ceramic coating}

The micro morphologies of the surface and cross section of the ceramic layer with different content of carbon nanotubes were shown in Fig. 3. It can be seen that there are many micropores formed by jet discharge channels on the coating surface, around which there are volcanic sedimentary particles and staggered CNTs which are rapidly cooled and solidified after melting. There are some tiny discharge micropores in the coating, on the one hand, the gas phase in the discharge channel is wrapped by molten 
oxide before being released during spark discharge; on the other hand, the plasma discharge forms the channel. Compared with the coating without CNTs, the plasma discharge micropores on the surface of PEO-CNTs composite coating are significantly reduced, because CNTs effectively fill the plasma discharge micropores.

It can be seen from the cross-section morphology that CPED coating and substrate are crisscross and well bonded. With the increase of CNTs content, the thickness of CPED ceramic coating gradually increases. Due to the addition of CNTs, the surface density of ceramic layer is increased, which is quite different from the coating without carbon nanotubes. The outer layer of the coating without carbon nanotubes is a loose layer. Compared with the inner layer, there are more micropores, and even some discharge through-holes are formed due to the high voltage continuous breakdown at the later stage of discharge. Because the CPED process includes not only plasma discharge process, but also electrodeposition process. During the electrodeposition process, CNTs fill a part of discharge channel, which improves the density of the coating surface.

In terms of cross-section morphology, with the increase of the concentration of carbon nanotubes, the appearance of discharge channel on the surface of CPED ceramic layer gradually changes from flat micropore to more convex crater. The discharge channel gradually decreases, the micropore diameter becomes larger, and the molten oxide increases. The results show that CNTs promote the cathode plasma discharge to some extent.

\subsection{Phase analysis of CPED ceramic coating}

X-ray diffraction patterns of coatings with different contents of CNTs were shown in Fig. 4. As seen in Fig. 4, CPED ceramic layer is mainly composed of a- $-\mathrm{Al}_{2} \mathrm{O}_{3}, \mathrm{t}-\mathrm{ZrO}_{2}, \mathrm{Zr}_{3} \mathrm{Y}_{4} \mathrm{O}_{12}$ and $\mathrm{SiO}_{2}$ phases. The diffraction peaks of $\mathrm{a}-\mathrm{Al}_{2} \mathrm{O}_{3}$ and $\mathrm{t}-\mathrm{ZrO}_{2}$ increase with the increase of CNTs concentration.

The results show that with the increase of CNTs concentration, the energy of micro arc discharge increases and the reaction temperature is high. When the melt meets the cold electrolyte and condenses rapidly, part of the high-temperature phases can't take place phase transition, which results in the increase of $\mathrm{a}-\mathrm{Al}_{2} \mathrm{O}_{3}$ and $\mathrm{t}-\mathrm{ZrO}_{2}$ content.

There are three crystalline states of zirconia, which are stable in the form of monoclinic $\mathrm{m}-\mathrm{ZrO}_{2}$ at room temperature, mainly tetragonal $\mathrm{t}-\mathrm{ZrO}_{2}$ at $1170-2370{ }^{\circ} \mathrm{C}$, while cubic $\mathrm{c}-\mathrm{ZrO}_{2}$ at $2370-2680{ }^{\circ} \mathrm{C}$. The corresponding phase transition occurs in different temperature ranges. The transformation of $\mathrm{t}-\mathrm{ZrO}_{2}$ to $\mathrm{m}$ $\mathrm{ZrO}_{2}$ is accompanied by a volume expansion of $3-5 \%$. This volume expansion can cause high residual stress and microcracks, which will lead to the destruction and peeling off of the coating. In order to prevent the phase transition, it is necessary to stabilize the high temperature phase to room temperature. The content of $\mathrm{t}-\mathrm{ZrO}_{2}$ in the coating is high and $\mathrm{Y}_{2} \mathrm{O}_{3}$ is contained in the coating. $\mathrm{Y}_{2} \mathrm{O}_{3}$ can make $\mathrm{t}-\mathrm{ZrO}$ stable at room temperature during cathodic plasma electrodeposition. 


\subsection{Growth rate of CPED ceramic coating}

The growth rate and thickness variation of the ceramic layer is shown in Fig. 5 . It can be seen that the growth rate of ceramic layer increases first and then decreases. CNTs can reduce the arc discharge voltage and promote the cathode plasma discharge, so it can promote the film formation to some extent. However, when the content increases to a certain extent, the sealing of the discharge micropores will make the discharge difficult and the film forming rate will decrease.

\subsection{Insulation temperature of ceramic coatings}

Because the thermal conductivity of $\mathrm{ZrO}_{2}$ is relatively low, the thermal conductivity of solid $\mathrm{ZrO}_{2}$ is in the range of $2 \mathrm{~W} /(\mathrm{m} \cdot \mathrm{K})$ to $4 \mathrm{~W} /(\mathrm{m} \cdot \mathrm{K})$, while the thermal conductivity of porous $\mathrm{ZrO}_{2}$ is lower, in the range of $0.5 \mathrm{~W} /(\mathrm{m} \cdot \mathrm{K})$ to $2 \mathrm{~W} /(\mathrm{m} \cdot \mathrm{K})$, which significantly improves the insulation temperature of ceramic layer. In addition, it can be seen from the XRD pattern that the increase of CNTs concentration improves the phase content of $\mathrm{a}-\mathrm{Al}_{2} \mathrm{O}_{3}$ and $\mathrm{t}-\mathrm{ZrO}_{2}$, so the thermal insulation performance is improved. On the other hand, CNTs can effectively fill the micropores of plasma discharge and increase the number of closed pores on the coating surface. The sealed micropores reduce the thermal conductivity and improve the thermal insulation performance of the coating.

\subsection{Fracture toughness and bending strength of ceramic coatings}

\subsection{Mechanism of CPED ceramic coating toughened by CNTs}

When the thermal protective coating works at high temperature, the change of temperature will cause thermal stress in the coating. When the thermal stress exceeds the critical fracture stress, the crack will propagate unsteadily and the coating will fail and peel off. The criteria of brittle ceramic coating cracking and peeling are as follows:

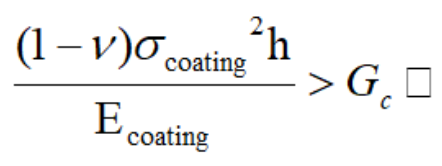

$\mathrm{E}_{\text {coating }}$ is the elastic modulus of the coating, $v$ is the Poisson's ratio of the coating, $h$ is the thickness of the coating, $\sigma_{\text {coating }}$ is the thermal stress of the coating, and $\mathrm{Gc}$ is the fracture toughness in the form of energy. When the coating material meets the formula, the peeling failure of the coating can be avoided. It can be seen that there are two ways to avoid coating peeling failure when the thickness of the coating is 
fixed. One is to reduce the driving force of crack initiation and propagation, that is, to reduce $\sigma_{\text {coating; }}$; the other is to improve the fracture toughness Gc of the coating by means of toughening.

Because the content of CNTs deposited in the coating is small, it has little effect on the phase transition sintering and thermal expansion coefficient of the coating, so it is difficult to reduce the thermal stress in the coating by slowing down the phase change sintering of the coating or increasing the thermal expansion coefficient of the coating. Therefore, the failure of the coating can be avoided by toughening the ceramic coating and improving the fracture toughness of the coating.

CNTs have many toughening and reinforcing mechanisms, such as bridging toughening, crack deflection and nanotube pull-out. CNTs with superplasticity and high toughness can pull two crack surfaces like a bridge. Figure 8(a) and Fig. 9(a) show the mechanism of the bridging toughening of CNTs. Figure 8(b) and Fig. 9(b) show the pull-out toughening mechanism of CNTs. When the crack continues to expand, it can absorb energy to prevent further crack growth, as shown in Fig. 8(a) and Fig. 9(a). When the fracture strength of CNTs exceeds the expansion stress of the crack, the crack will deviate from the original direction due to the weak interface between the CNTs and the coating. The crack will propagate along the interface between the CNTs and the coating, and eventually lead to the interface dissociation. In the process of dissociation, when the CNTs are pulled out, they will rub with the interface, absorb the energy of crack growth, and prevent the crack from continuing to expand, which plays a certain role in toughening, as shown in Fig. 8 (b) and Fig. 9 (b). When the tensile stress is greater than the breaking strength of the CNTs, the crack tensile stress will break the CNTs. The crack growth path is zigzag, which has larger surface energy than plane crack. So it can absorb more energy and play a toughening effect, as shown in Fig. 8 (c).

In addition, due to the CNTs in the ceramic coating and the formation characteristics of the ceramic coating, a large number of microcracks will form in front of the ceramic coating when the crack propagates. Microcracks improve the fracture toughness of ceramic coatings by absorbing the energy of lattice strain and relieving the stress concentration at the crack tip. Therefore, the superplastic and highly ductile CNTs can improve the fracture toughness of the coating.

In addition, according to Griffith fracture theory, fracture toughness can be expressed by formula (2). $K_{\mathrm{IC}}$ is the fracture toughness expressed by the stress field intensity factor, $\sigma_{\mathrm{c}}$ is the critical crack growth stress, $a$ is the half length of the crack.

$$
\mathrm{K}_{\mathrm{IC}}=\sigma_{\mathrm{c}} \sqrt{\mathrm{a}}
$$

The more CNTs are dispersed in a unit volume of ceramic coating, the greater the resistance of crack to CNTs in the process of propagation, and the smaller the average size of crack. Therefore, the toughening effect of ceramic coating will be improved, and the fracture toughness will be better. In addition, Rice's 
research on the toughening mechanism of particle doping shows that if there are too many toughening particles in the coating, the particles may agglomerate. At this time, the toughening effect of continuing to increase the number of particles on the coating will be very limited.

\section{Conclusions}

The microstructure, thermal insulation and fracture toughness of CPED ceramic coating modified by CNTs were studied. CNTs are evenly and crisscross distributed in the ceramic coating, which can effectively fill the micropores of plasma discharge, and the evenly closed micropores can effectively improve the thermal insulation performance of the ceramic coating. To some extent, CNTs can promote the cathode plasma discharge and improve the film formation rate. The content of $\mathrm{a}-\mathrm{Al}_{2} \mathrm{O}_{3}$ and $\mathrm{t}-\mathrm{ZrO} \mathrm{O}_{2}$ phases increased with the increase of CNTs concentration. A certain amount of CNTs can effectively improve the insulation temperature of ceramic coating. With the increase of the content of CNTs, the fracture toughness and bending strength gradually increase. CNTs can improve the mechanical properties of the ceramic coating through the mechanism of bridging, crack deflection and nanotube pullout toughening.

\section{Declarations}

\section{Acknowledgment}

This research work is financially supported by the Youth Innovation Team of Shaanxi Universities: Metal corrosion protection and surface engineering technology, the National Natural Science Foundation of China (51771140), Industrial field project of Shaanxi provincial science and technology department (2018GY-111), Shaanxi provincial department of education industrialization cultivation project (17JF009) and Yulin science and technology project (2018-2-30).

\section{References}

1. Li MH, Wang DR, Xue JC, Jia RX. Direct preparation of $\mathrm{Y}_{3} \mathrm{Al}_{5} \mathrm{O}_{12}$ hollow microspheres using cathode plasma electrolytic deposition. Ceram Int. 2019;45:24919-22.

2. Xue JC, Wang DR, Li MH, Jia RX. Preparation of silicon-modified gamma alumina coating through cathodic plasma electrolytic deposition. Ceram Int. 2019;45:19345-50.

3. Quan C, Deng SJ, Jiang YD, Jiang C, Shuai MB. Characteristics and high temperature oxidation behavior of $\mathrm{Ni}-\mathrm{Cr}-\mathrm{Y}_{2} \mathrm{O}_{3}$ nanocomposite coating prepared by cathode plasma electrolytic deposition. $\mathrm{J}$ Alloy Compd. 2019;793:170-8.

4. Wang P, Yuwen QQ, Li JP. The differences in the formation mechanism of PEO and CPED composited ceramic coatings on Al-12Si alloy. J Alloy Compd. 2019;788:61-6.

5. Wang P, Li JP, Ma ZJ, Gao PH. The growth mechanism of CPED coating with zirconia sol addition on an Al-12Si alloy. Journal of Alloys compounds. 2018;740:735-42. 
6. Ji RN, Peng GC, Zhang SG, Li Z, Wu JS. The fabrication of a $\mathrm{CeO}_{2}$ coating via cathode plasma electrolytic deposition for the corrosion resistance of AZ31 magnesium alloy. Ceram Int. 2018;44:19885-91.

7. Huang JW, Zhu JY, Fan XM, Xiong DS, Li JL. Preparation of $\mathrm{MoS}_{2}-\mathrm{Ti}(\mathrm{C}, \mathrm{N})-\mathrm{TiO}_{2}$ coating by cathodic plasma electrolytic deposition and its tribological properties. Surface Coatings Technology. 2018;347:76-83.

8. Wang Y, Cao XQ, Zhang Z, Huang K, Wu JS. Formation and wear performance of diamond-like carbon films on $316 \mathrm{~L}$ stainless steel prepared by cathodic plasma electrolytic deposition. Diam Relat Mater. 2019;95:135-40.

9. Wang $\mathrm{SQ}$, Xie FQ, Wu XQ. Mechanism of $\mathrm{Al}_{2} \mathrm{O}_{3}$ coating by cathodic plasma electrolytic deposition on TiAl alloy in $\mathrm{Al}\left(\mathrm{NO}_{3}\right)_{3}$ ethanol-water electrolytes. Mater Chem Phys. 2017;202:114-9.

10. Zhang SG, Zhang J, Ji RN, Lian Y, He YD. The effect of electric conductivity on the structure of ceramic coatings prepared by cathode plasma electrolytic deposition. Mater Chem Phys. 2019;224:36-9.

11. Ma LZ, Huang JW, Fan XM, Li JL, Xiong DS. Properties of thick ceramic composite coatings synthesized on an aluminium alloy by cathodic plasma electrolytic deposition. Surface Coatings Technology. 2018;356:80-8.

12. Wang $L X$, Wang DR. Study on energy consumption of $\mathrm{Al}_{2} \mathrm{O}_{3}$ coating prepared by cathode plasma electrolytic deposition. Ceram Int. 2018;44:657-62.

13. Wang P, Deng SJ, He YD, Liu CX, Zhang J. Oxidation and hot corrosion behavior of $\mathrm{Al}_{2} \mathrm{O}_{3} / Y S Z$ coatings prepared by cathode plasma electrolytic deposition. Corros Sci. 2016;109:13-21.

14. Shi RX, Li J, Yin YS, Ge HY. Toughening mechanisms and microstructure of $\mathrm{Al}_{2} \mathrm{O}_{3}$-TiC-Co composites. Materials Science Engineering: A. 2011;528:5341-7.

15. Deng SJ, Wang P, He YD, Zhang J. Thermal barrier coatings with $\mathrm{Al}_{2} \mathrm{O}_{3}-\mathrm{Pt}$ composite bond-coat and $\mathrm{La}_{2} \mathrm{Zr}_{2} \mathrm{O}_{7}$-Pt top-coat prepared by cathode plasma electrolytic deposition. Surface Coatings Technology. 2016;291:141-50.

16. Li MH, Wang DR, Xue JC, Jia RX. Preparation of Pd-doped $\mathrm{Y}_{3} \mathrm{Al}_{5} \mathrm{O}_{12}$ thermal barrier coatings using cathode plasma electrolytic deposition. Ceram Int. 2020;46:7019-24.

17. Liu CX, Zhang SG, Ji RN, Wang P, He YD. Cathode plasma electrolytic deposition of $\mathrm{Al}_{2} \mathrm{O}_{3}$ coatings doped with SiC particles. Ceram Int. 2019;45:4747-55.

18. Wang $\mathrm{SQ}$, Xie FQ, Wu XQ, Chen $\mathrm{LY}$. $\mathrm{CeO}_{2}$ doped $\mathrm{Al}_{2} \mathrm{O}_{3}$ composite ceramic coatings fabricated on $\mathrm{Y}^{-}$ TiAl alloys via cathodic plasma electrolytic deposition. J Alloy Compd. 2019;788:632-8.

19. Zhong XH, Zhao HY, Zhou XM, Liu CG, Wang L. Thermal shock behavior of toughened gadolinium zirconate/YSZ double-ceramic-layered thermal barrier coating. J Alloy Compd. 2014;593:50-5.

20. Ma XX, He YD, Wang DR. Preparation and high-temperature properties of Au nano-particles doped alpha- $\mathrm{Al}_{2} \mathrm{O}_{3}$ composite coating on TiAl-based alloy. Appl Surf Sci. 2011;257:10273-81. 
21. Wang P, He YD, Deng SJ, Zhang J. Porous a- $\mathrm{Al}_{2} \mathrm{O}_{3}$ thermal barrier coatings with dispersed Pt particles prepared by cathode plasma electrolytic deposition. International Journal of Minerals Metallurgy Materials. 2016;23:92-101.

22. Liu Y, Ramirez C, Zhang L, Wu WW, Padture NP. In situ direct observation of toughening in isotropic nanocomposites of alumina ceramic and multiwall carbon nanotubes. Acta Mater. 2017;127:20310.

23. AsI MS, Farahbakhsh I, Nayebi B. Characteristics of multi-walled carbon nanotube toughened $\mathrm{ZrB}_{2}{ }^{-}$ SiC ceramic composite prepared by hot pressing. Ceram Int. 2016;42:1950-8.

24. Liu Q, Lomov SV, Gorbatikh L. The interplay between multiple toughening mechanisms in nanocomposites with spatially distributed and oriented carbon nanotubes as revealed by dual-scale simulations. Carbon. 2019;142:141-9.

25. Ahmad K, Pan W. Microstructure-toughening relation in alumina based multiwall carbon nanotube ceramic composites. J Eur Ceram Soc. 2015;35:663-71.

26. Xiang YY, Wang XJ, Hu XS, Meng LL, Wu K. Achieving ultra-high strengthening and toughening efficiency in carbon nanotubes/magnesium composites via constructing micro-nano layered structure. Compos Part A: Appl Sci Manufac. 2019;119:225-34.

27. Ariharan S, Nisar A, Balaji N, Aruna ST, Balani K. Carbon nanotubes stabilize high temperature phase and toughen $\mathrm{Al}_{2} \mathrm{O}_{3}$-based thermal barrier coatings. Composites Part B: Engineering. 2017;124:76-87.

28. Fu QG, Zhuang L, Ren QW, Feng L, Guo YA. Carbon nanotube-toughened interlocking buffer layer to improve the adhesion strength and thermal shock resistance of $\mathrm{SiC}$ coating for $\mathrm{C} / \mathrm{C}-\mathrm{ZrC}-\mathrm{SiC}$ composites. Journal of Materiomics. 2015;1:245-52.

\section{Figures}




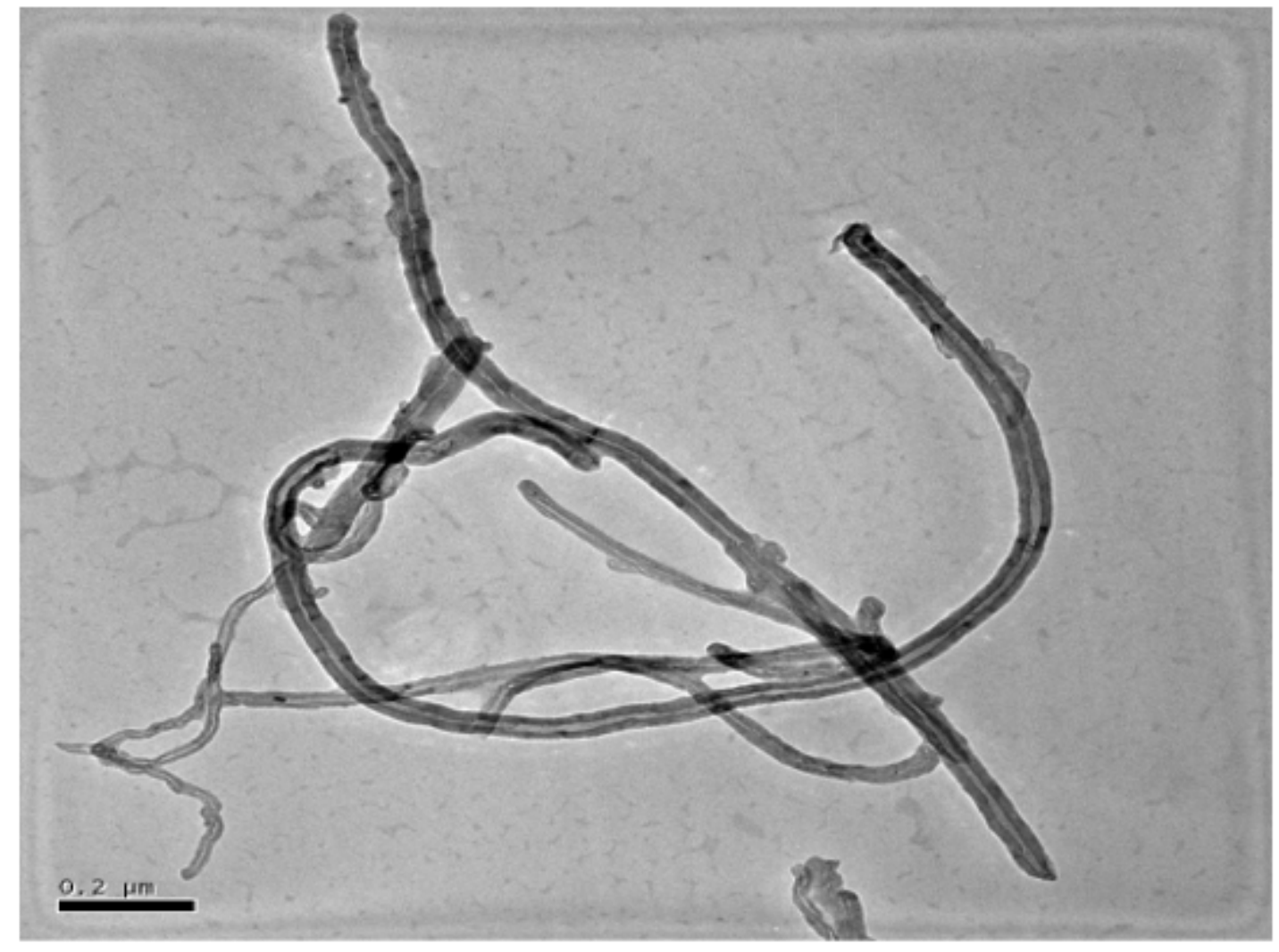

Figure 1

TEM micrograph of CNTs 


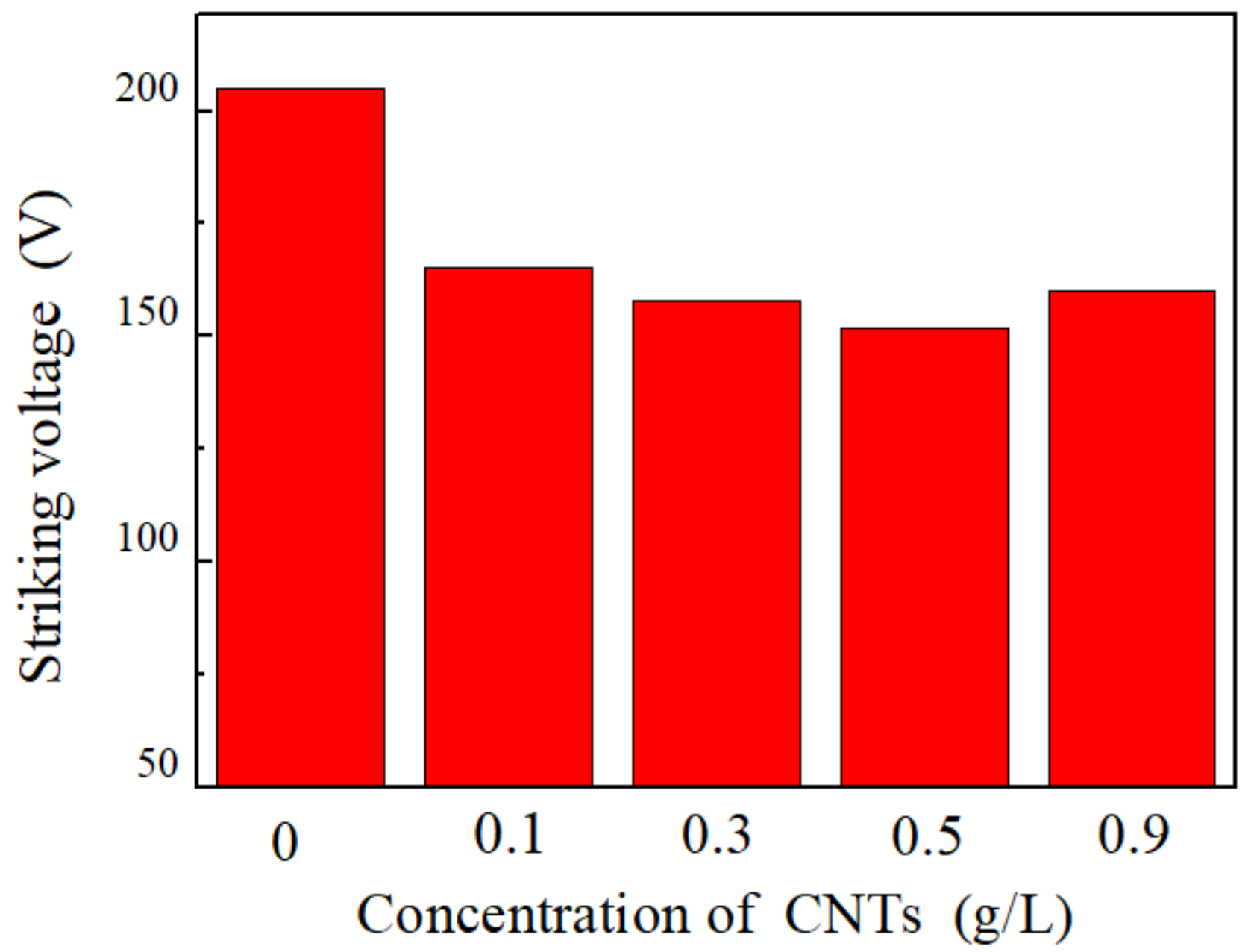

Figure 2

Arc discharge voltage with different content of CNT 

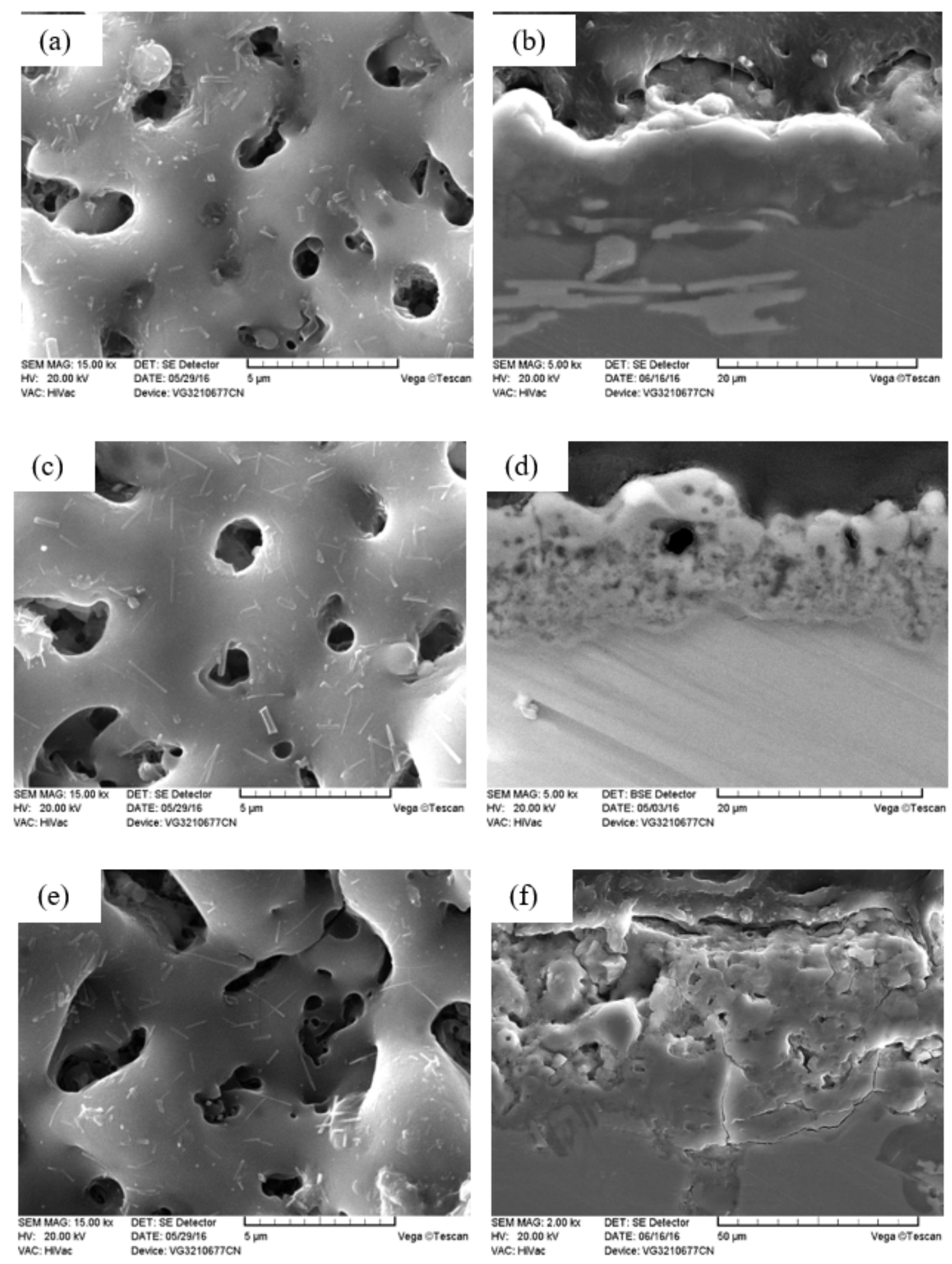

\section{Figure 3}

Morphology of CPED ceramic coatings with different concentrations of CNTs (a), (b) $0.3 \mathrm{~g} / \mathrm{L}$ CNTs; (c), (d) $0.5 \mathrm{~g} / \mathrm{L} \mathrm{CNTs;} \mathrm{(e),} \mathrm{(f)} 0.9 \mathrm{~g} / \mathrm{L}$ CNTs 


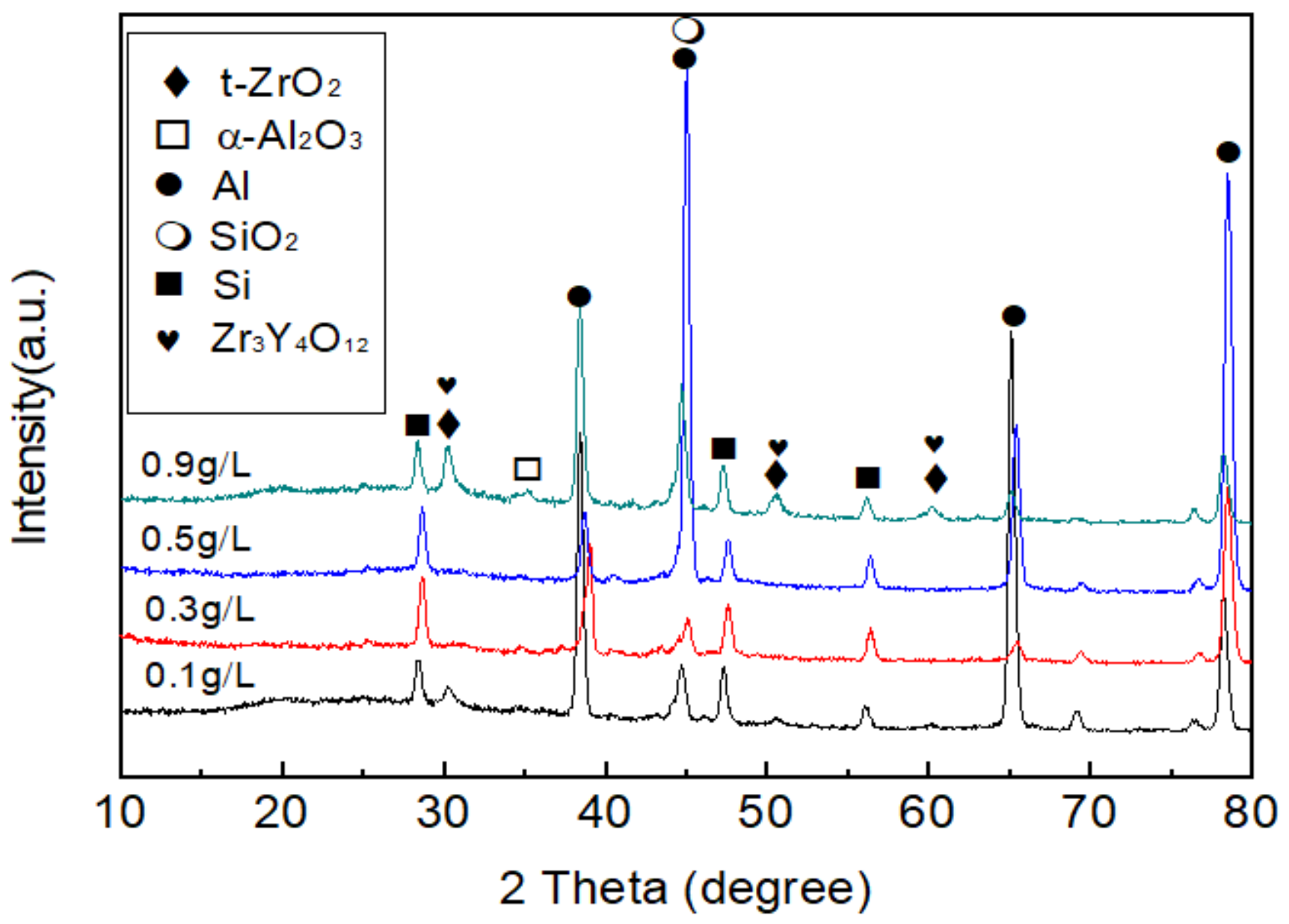

Figure 4

X-ray diffraction patterns of coatings with different contents of CNTs 


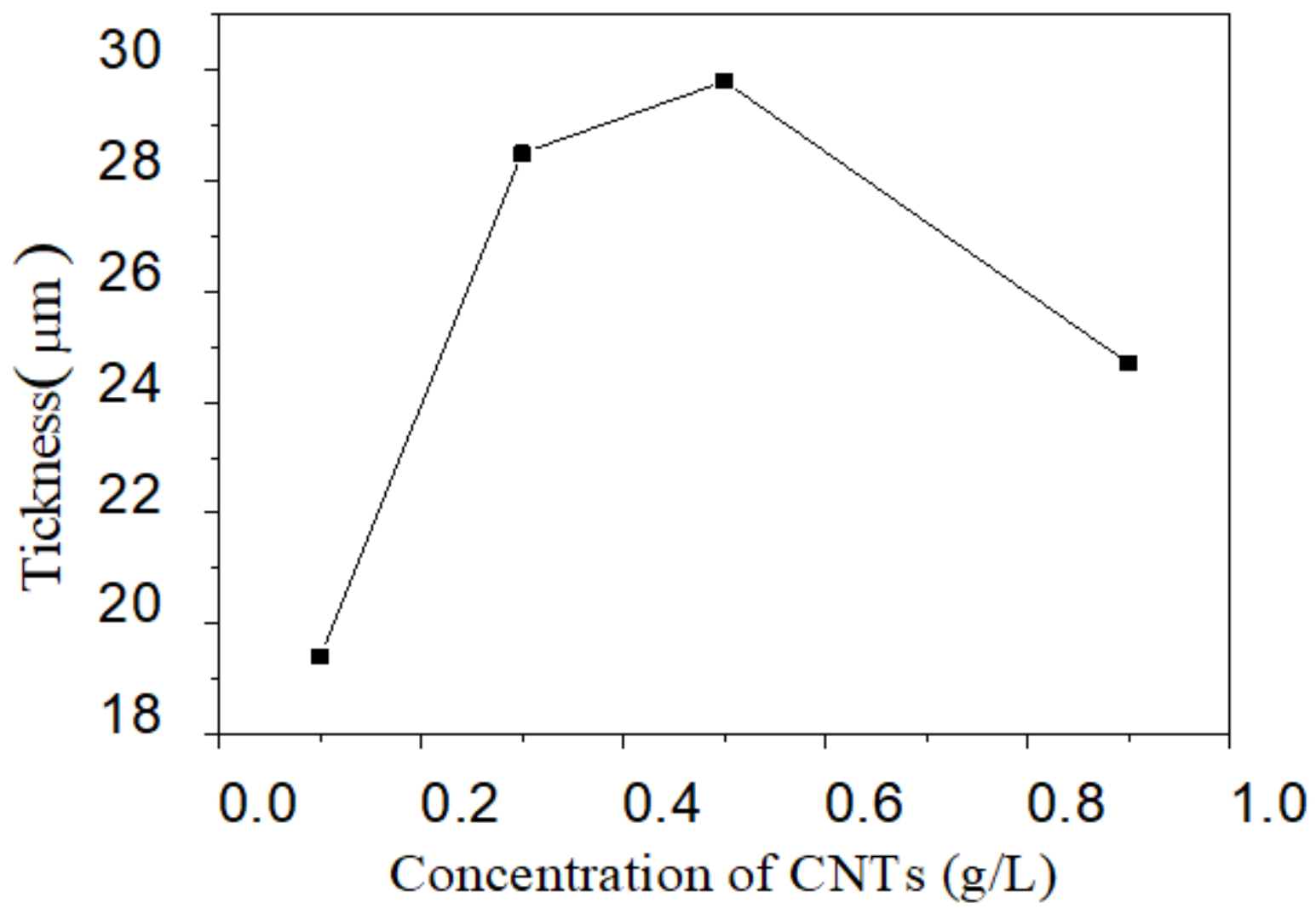

Figure 5

Thickness variation of the ceramic layer with different contents of CNTs 

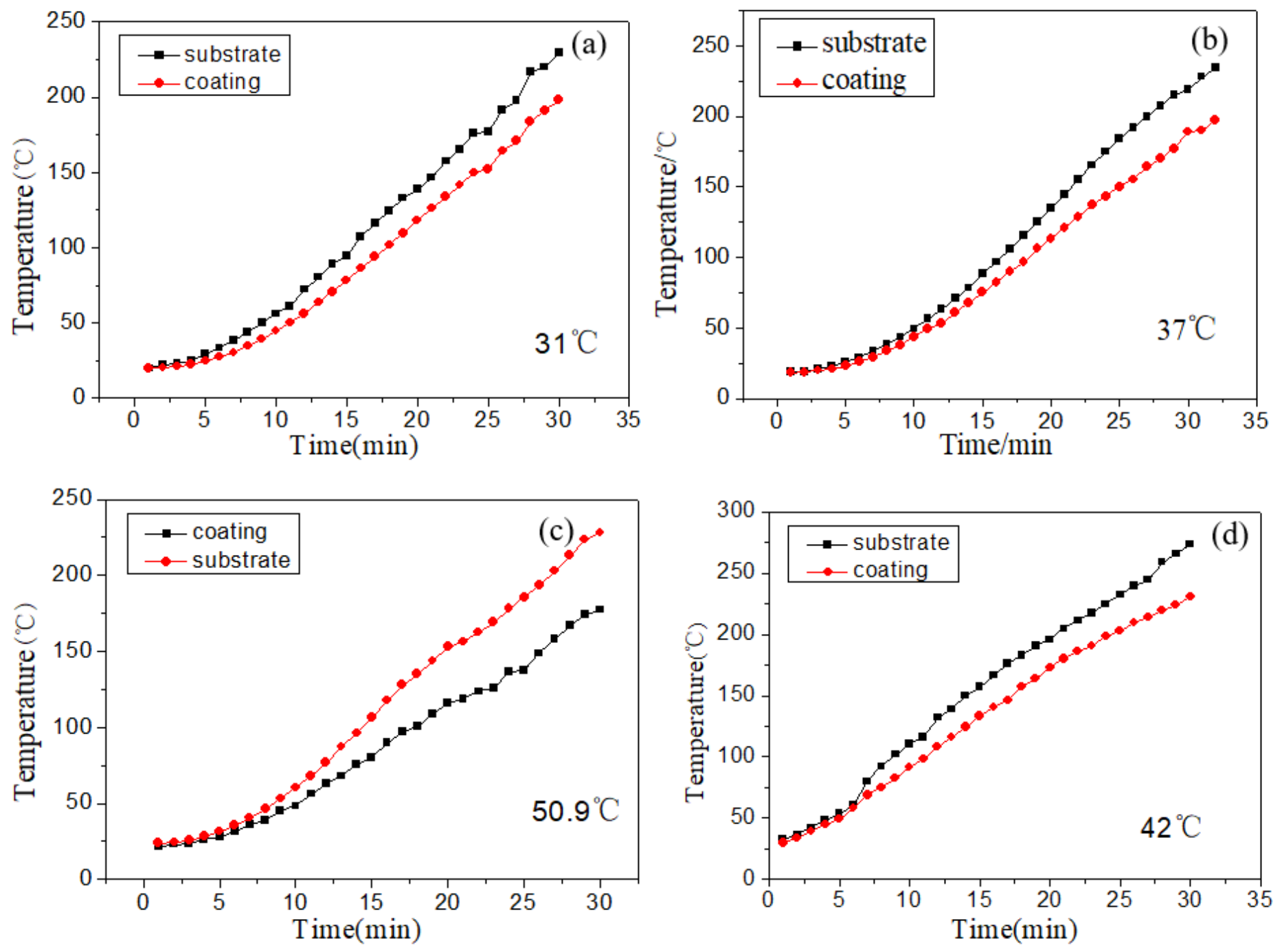

Figure 6

Heat-insulating temperature test of CPED coatings for different CNTs concentrations: (a) $0.1 \mathrm{~g} / \mathrm{L}$; (b) 0.3 $\mathrm{g} / \mathrm{L}$; (c) $0.5 \mathrm{~g} / \mathrm{L}$ and (d) $0.9 \mathrm{~g} / \mathrm{L}$. 


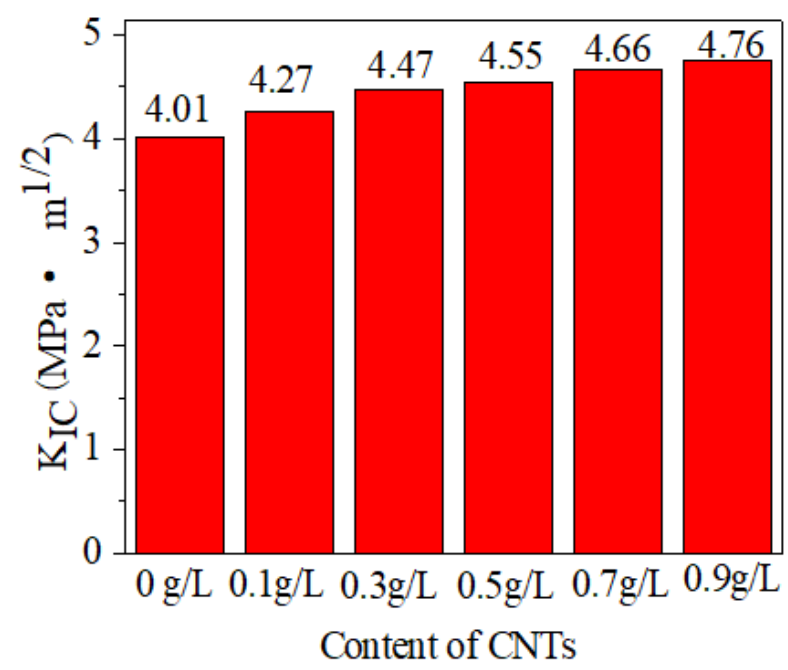

(a) Fracture toughness

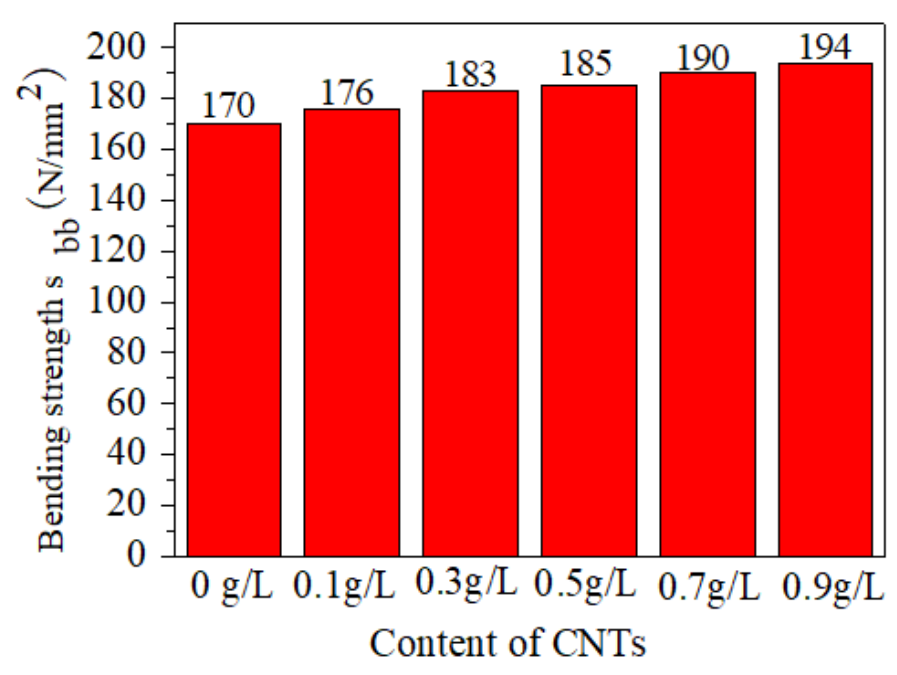

(b) Bending strength

Figure 7

Fracture toughness and bending strength of ceramic coatings 


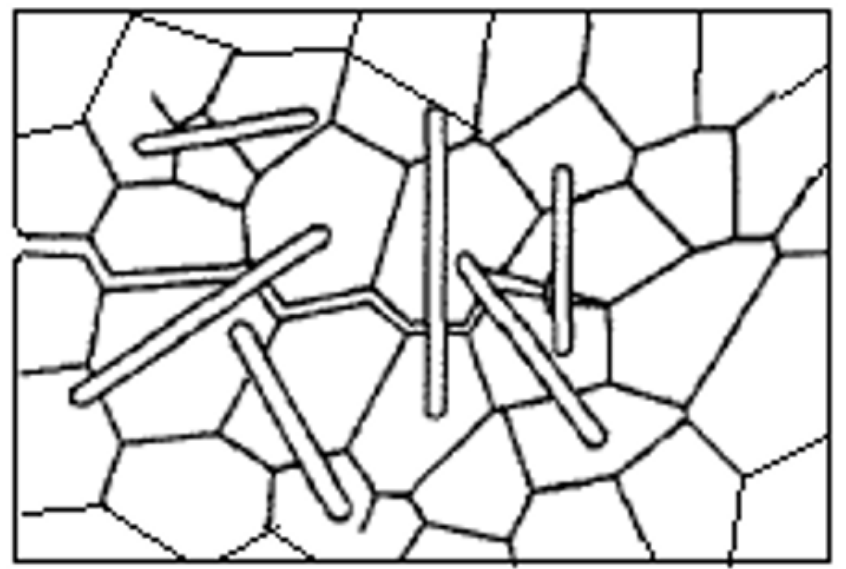

(a) Bridge toughening mechanism

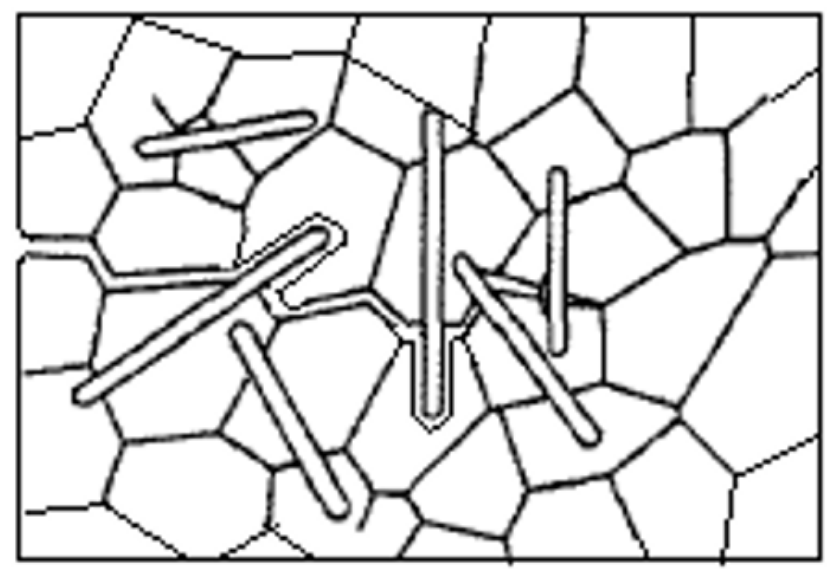

(b) Mechanism of pull-out toughening

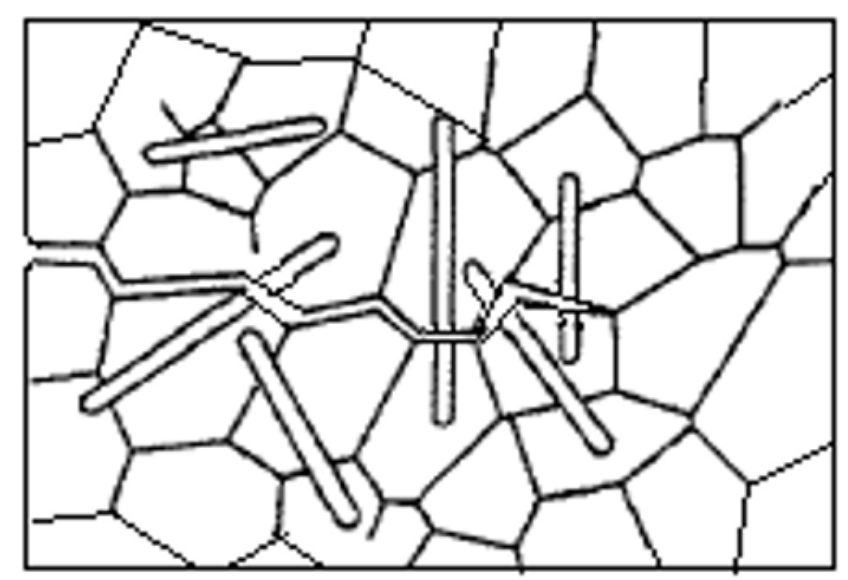

(c) Mechanism of crack deflection toughening

Figure 8

Toughening mechanism model of $\mathrm{CN}$ 


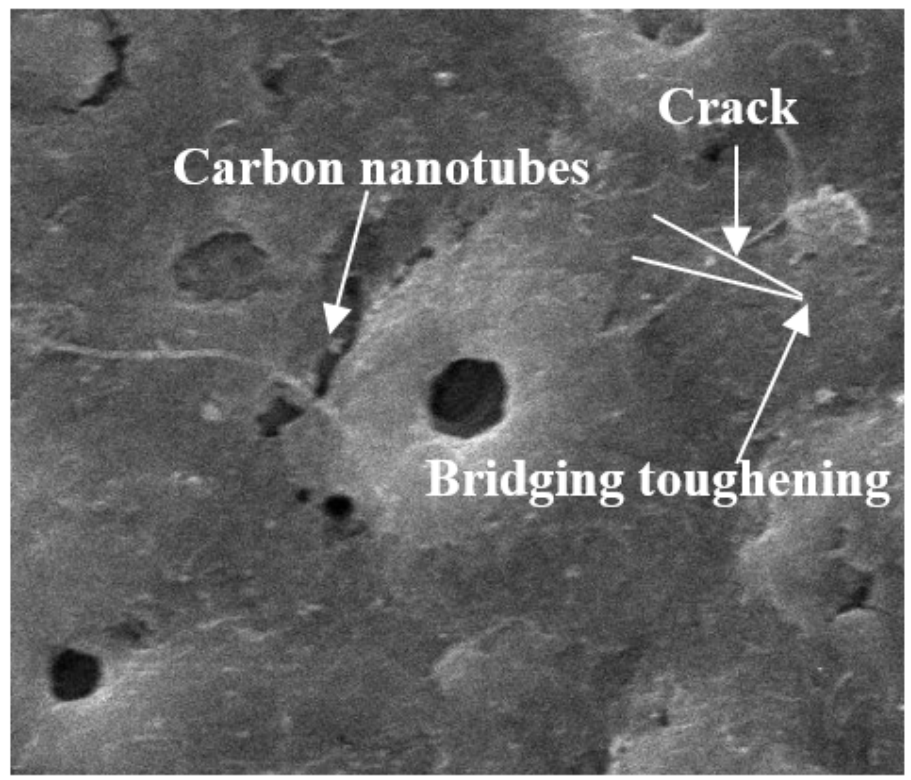

(a) Bridging toughening of CNTs

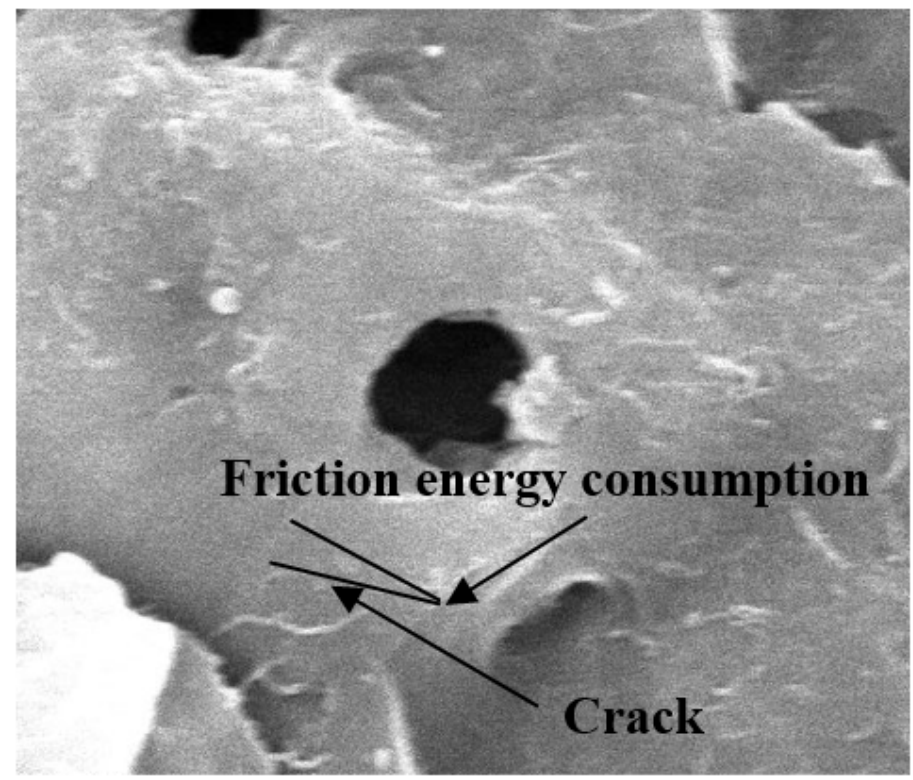

(b) Pull-out toughening of CNTs

Figure 9

Toughening mechanism of Pt particles 